SILVANA LADO

ANA NUÑEZ

ANA LÍA VERÓN

\title{
FRAGMENTACIÓN INSTITUCIONAL DEL CAMPO URBANO Y PODER SIMBÓLICO
}

\author{
Las autoras pertenecen al Grupo de Investigación en Socio Antropología (GISAU) del Centro de Estudios Históricos \\ Arquitectónicos Urbanos de la Facultad de Arquitectura, Urbanismo y de Diseño. UNMdP (Argentina).
}

\begin{abstract}
RESUMEN. Nuestra investigación intenta comprender, transdisciplinariamente, el proceso de construcción de la ciudad buscando responder ¿cómo se cargan de significación los espacios urbanos? ¿cómo se construyen y transforman las identidades locales en el proceso de apropiación del espacio urbano? ¿cómo se elabora y modifica el sentido de pertenencia? y ¿cuál es el rol de las instituciones en este proceso?. Nuestro objetivo principal es analizar la expansión urbana en ciudades intermedias, desde la segunda mitad del siglo XX, a partir de las estrategias de los actores sociales involucrados, en el doble proceso de construcción de identidades colectivas y de apropiación del espacio. Nuestra hipótesis es que la identidad, como construcción en la que los sujetos se reconocen en una espacialidad y una temporalidad determinada, está en estrecha relación con la diferente estructura y volumen de capital que los actores sociales tienen que reproducir en ese proceso.
\end{abstract}

\section{ABSTRACT. URBAN FRAGMENTATION AND SYMBOLIC POWER.}

This article attempts to elucidate the process making of the city throughout a multidisciplinary approach. It tries to answer the following questions; How urban spaces are signified?; How local identities are built up and transformed within a process of urban spaces 'appropriateness'?; How these 'appropriateness' are elaborated and modified?; And finally, how institutions played its role in the 'appropriateness' process?

The article aim to analyses the urban expansion of medium-sized towns, since mid-XXth century onward. In doing so, urban actors' strategies are taken under consideration in both trends, as in sort of double and interconnected trends as collective identities constructors and spatial appropriation.

It is argued that identity is a process where individuals recognize each other within a given spatiality in time. This has tightened the link with their differentiated capital structure and amounts to which each person's have to reproduce within that process.

\section{INTRODUCCIÓN}

La discusión respecto al significado polisémico del concepto de barrio lleva varias décadas instalada desde diversos campos de las ciencias sociales. Una línea de trabajo es la que se centra en la vinculación entre el Estado municipal y los vecinos, la cual fue resuelta, tradicionalmente en Argentina, a partir de la organización y división socio espacial en Sociedades de Fomento, Sociedades vecinales o Comisión de vecinos. Esta estrategia de asignar fragmentos de territorio constituyentes de la ciudad a un tipo de organización vecinal, ha sido, en general, pautada desde el Estado y cualifica y cuantifica de una determinada manera el espacio urbano.

Desde este ángulo, es posible visualizar no sólo diversas posiciones respecto a la definición de lo barrial sino también la emergencia de ciertos conflictos.

La primera estaría conformada por la manera como desde el municipio se comprenden "los problemas barriales", "los barrios" y, por ende, las políticas "para los barrios", es decir, el significado que atribuyen los funcionarios a estos conceptos. Por otro lado, nos interesa conocer cual es la concepción que los vecinalistas o fomentistas tienen acerca del barrio. Finalmente, resulta importante al análisis la 
perspectiva de los vecinos, en tanto habitantes de un espacio subdividido administrativamente, y en diferentes escalas, de manera superpuesta por las diversas jurisdicciones sociopolíticas.

El objetivo de este trabajo es presentar la manera cómo el Estado municipal ha fragmentado el espacio de la ciudad de Mar del Plata desde una perspectiva histórica, tomando como fuente las diversas experiencias y normativas vinculadas a la relación Estado/vecinos. Esto nos permitirá visualizar la relación existente entre el modo cómo se expande la ciudad y las decisiones municipales sobre cómo organizar y controlar los problemas urbanos resultantes de dicho crecimiento urbano.

Nuestra hipótesis es que esta estrategia desde el Estado se inscribe en la lógica del poder simbólico, al otorgar un lugar institucional a quienes están excluidos del consumo urbano. Esta institucionalización doblega las fuerzas de un espacio social heterogéneo, plausible de luchar contra la centralidad de la contradicción del modo de producción capitalista. Su contracara, la autogestión, tiene un contenido productivista y socializador. Implica un trastocamiento de la política instituida, de la noción de centro. La autogestión daría lugar a la decadencia del Estado y a un proceso de su gradual desaparición (Laurou, 1993).

En este contexto, las asociaciones vecinales serían una institución necesaria del sistema capitalista, pasando a ser una organización burocratizada, que media entre los habitantes y el Estado, delegando en los primeros la construcción de las dimensiones inherentes a la reproducción de la fuerza de trabajo y al segundo las referidas a la reproducción del capital.

Necesariamente, esta disociación encubierta en la unificación barrial apela a factores inscriptos en lo simbólico porque se participa imaginariamente del poder pero se está excluido del control y la decisión. Es una integración imaginaria en el sistema que permite la construcción, a nivel del imaginario colectivo, de representaciones de la realidad social que facilitan la aceptación de la ideología dominante. Así se intenta inhibir toda expresión de transformación y el imaginario colectivo oculta la otra realidad estructural de la dominación. En síntesis, el poder se consolida cuando la asimetría se institucionaliza en estructuras jerárquicas (Bértolo, 1993).

Para Bourdieu, el poder simbólico es el poder invisible que no puede ejercerse sino con la complicidad de los que no quieren saber que lo sufren o incluso que lo ejercen. Es un poder de construcción de la realidad que tiende a establecer un orden gnoseológico (el conformismo lógico de Durkheim). Compartir un sistema simbólico, una concepción homogénea del tiempo y del espacio hace posible el acuerdo, la solidaridad social. Es la función social del simbolismo. Se define en y por una relación determinada entre los que ejercen el poder y los que lo sufren. Es una forma transformada de las otras formas de poder, lo cual resulta inescindible, en nuestra opinión, de la hegemonía gramsciana, porque da movilidad a las relaciones entre distintos niveles de la estructura social y política y porque problematiza la relación entre base y superestructura. La hegemonía no es sólo dominación política sino dirección ideológico-cultural: es control e imposición no forzada para crear el consenso (Graner, 1991).

Marx sostiene que el poder simbólico tiene, además, una función política al relacionarlo con los intereses de la clase dominante, porque integra a ésta realmente pero integra ficticiamente a la sociedad en su conjunto (Ansart, 1993).

\section{LAS PRIMERAS EXPERIENCIAS DE ASOCIATIVISMO EN MAR DEL PLATA}

La ciudad de Mar del Plata, fundada hacia 1874, se constituyó rápidamente en una ciudad balnearia, reducto elegido por la élite porteña como una opción diferente a la huida a las quintas de la zona norte de Buenos Aires ante la epidemia de fiebre amarilla.

Hacia fines del siglo XIX los primeros gobiernos municipales manifestaban la preocupación característica de la época vinculada a las ideas de "higienismo y salud"[1]. Por este motivo es que decide fomentar la creación de comisiones de vecinos que colaboren con la inspección, denuncia, limpieza, control y ejecución de obras de saneamiento. Para la organización normativa de dichas comisiones se decide la división del Partido de General Pueyrredón (en adelante, PGP) en cinco cuarteles, cada uno a cargo de un alcalde[2] y, al mismo tiempo, otra división de carácter higienista en 
tres secciones, en cada una de las cuales se nombra una comisión de vecinos que elegirán un presidente y un secretario.[3]

El gobierno municipal otorga de esta forma un marco legal para la participación de los vecinos y establece la modalidad del vinculo, imponiendo la posesión de un determinado capital cultural que condiciona de algún modo la participación. En estas acciones se entiende a los vecinos como agentes promotores de cambios en la gestión urbana, definiéndolos literalmente como "el agente del progreso urbano y rural, como socio de la municipalidad y como posible contribuyente con aportes de capital en forma libre".

Un antecedente importante en la relación Estado/vecinos, por el impacto que tuvo en el desarrollo urbano, fue la Comisión Pro-Mar del Plata, que comienza su obra el 14 de febrero de 1920. El objetivo de su constitución fue la preocupación y crítica de ciertos agentes influyentes de la elite porteña y local "por el abandono en el que había caído la ciudad y el balneario, librados a su propia suerte por todas las fuerzas que antes habían coadyuvado a su conservación y desenvolvimiento".[4]

Siguiendo a Ferreira Dos Santos (1986), el evento que funciona como movilizador para la autoconvocatoria es el avance del mar que amenazaba con destruir la Rambla Bristol y la ausencia de medidas necesarias por parte del gobierno local para recuperar esas obras. Así, como producto de una necesidad sentida y ante la falta de respuesta municipal, la Comisión comienza " una verdadera obra de gobierno" para recuperar de su "estado ruinoso" las obras existentes en el balneario y para "continuar la obra de su progreso y engrandecimiento".

Íntimamente ligada a otras Instituciones importantes de Mar del Plata y Buenos Aires (debido a que los presidentes de éstas eran miembros naturales de la Comisión)[5] funcionó muchas veces como un gobierno paralelo de la ciudad, a la que describen como «un cuerpo con dos cabezas», logrando incluso el manejo de una partida presupuestaria de la Provincia de Buenos Aires y un subsidio de la Nación para la realización de obras.

Si bien la labor principal de la Comisión fueron las obras de recuperación de las playas, la Rambla, Bristol, el Paseo General Paz y paseos adyacentes a la costa, su visión del desarrollo urbano fue mas allá comprendiendo que debían atender otros asuntos que podían perjudicar la puesta en valor de la ciudad. Y es por esta visión más amplia de lo que consideraban progreso que se preocuparon, entre otras cosas, por las tarifas y frecuencias de los trenes, por el mejoramiento del servicio de tranvías, el edificio para el funcionamiento del Colegio Nacional, la extensión de las vacaciones escolares para alargar la temporada, la instalación de la base naval, protección de los trabajadores del puerto, mejoras de caminos, pavimentos, desagües, cloacas, usinas y los espigones de las playas de La Perla.

Hacia la segunda década del siglo XX se inicia una nueva etapa en la relación Estado/vecinos, producto de la instalación del socialismo en el gobierno municipal, que es paralelo al acelerado crecimiento urbano como resultado de la atracción de flujos migratorios internacionales primero e internos después, debido a las posibilidades que ofrecía el mercado laboral. En efecto, ya en 1914 no sólo ocupa el décimo lugar entre las ciudades más grandes del país, sino que mientras Argentina tenía $52.7 \%$ de población urbana y $30 \%$ de población extranjera, estos indicadores en el PGP, eran del $85.7 \%$ y $47.1 \%$, respectivamente. Este proceso, que la ha ubicado como una ciudad grande entre las intermedias, alcanza su mayor dinamismo en la década de 1950, cuando se radicaban en la ciudad 7 familias por día (Nuñez, 1998).

Estos nuevos habitantes llegan con sus habitus y prácticas participativas relacionadas con manifestaciones de solidarismo y fomentismo[6], con un ideario de libertad e igualdad y esperanza de transformación social radical. En otros términos, la utopía anarquista consiste en romper la membrana que separa el espacio simbólico del poder del espacio simbólico de la libertad (Laurou, 1993). Este capital simbólico que poseen los nuevos habitantes, constitutivo de sus instrumentos de reproducción, permite ubicarlos en un espacio social cuyos principios estructuradores de prácticas es necesario transformar para evitar el conflicto.

El actor social por excelencia era el movimiento obrero, cuyo mosaico político fundacional está conformado por socialistas y anarquistas y en la década del '30 también por comunistas. Si bien el espectro político gubernamental tenía una hegemonía liberal-conservadora, el socialismo en Mar del 
Plata, desde 1911 a 1930, ocupó un lugar de privilegio, desarrollando con mayor impulso prácticas asociativas y fomentistas que propugnaron el progreso de la ciudad en general y de todos sus segmentos barriales en particular.[7]

Es en este marco que se constituyen las primeras Asociaciones Vecinales, conformadas por vecinos que residen en espacios aun no consolidados, es decir, en zonas de la ciudad que aún mantenían su impronta rural. Estas asociaciones canalizaron las crecientes demandas de servicios y favorecieron la emergencia de un sentido de pertenencia. La conformación de barrios se inició como conjuntos de varias casas alejadas de otros núcleos de viviendas. El municipio, a través de las asociaciones vecinales, estableció un canal de comunicación para la presentación de los reclamos, centrados en la provisión de servicios de agua potable, desagües, alumbrado, apertura y pavimentación de calles y la mejora de condiciones de salubridad.

Así, en 1935 se sanciona la Ordenanza municipal titulada «Cooperación vecinal, Comisiones de Fomento», derogada en 1942 por la Ordenanza No. 314, que es la que se encuentra actualmente vigente.[8]

Ya desde 1935, se decreta la prohibición de federarse a las asociaciones de fomento, que va a perdurar durante mas de cincuenta años hasta que finalmente es derogado en 1990. Este hecho es relatado de la siguiente manera por un fomentista del actual Movimiento Vecinalista Marplatense "De Cara al País":

"La prohibición de federarse para la sociedades de fomento ha cruzado todas las administraciones comunales, civiles y militares, pero este tema jamás fue tocado. Sin embargo, las sociedades de fomento se fueron dando forma de agrupaciones que tenina que ver con lo zonal y paulatinamente se fueron agrupando. Quienes más contribuyeron al desarrollo de las sociedades fomentistas fueron las administraciones socialistas. Bronzini fue el primero que comenzó a realizar convenios con las entidades de fomento. Pero la parte fuerte del fomentismo comienza en la década del '50 en adelante y con mayor empuje en la década del '60, a través de la realización de Congresos, hasta la actualidad se realizaron 7 . A pesar de la vigencia de la Constitución que decía que todos los argentinos se podían asociar con fines útiles, existía este decreto".[9]

Otro antecedente de la fragmentación institucional del espacio lo constituye la creación de Delegaciones Municipales, a partir de 1948. Ahora bien, ¿ cómo se conjuga este proceso con la producción del espacio?

\section{ESTRATEGIA POLÍTICA Y EXPANSIÓN DE LA PLANTA URBANA}

Como dijimos, es en la década de 1920, que se vislumbra una incipiente preocupación política por la extensión de la planta urbana, es decir, el crecimiento de la ciudad se constituye en un problema:

"La municipalidad se preocupa por mejorar los servicios públicos porque la planta urbana se ensancha constantemente..."[10]

Sin embargo, los servicios más importantes de esta gestión consistieron en la provisión de alumbrado público y pavimento. Es de destacar que los conflictos partidarios entablados entre el municipio y la provincia, trabaron políticamente la gestión socialista, originando que aquel funcionara con muy pocos recursos, mas allá de los recaudados directamente.[11]

Analizando la planta urbana construida de 1935, en un período municipal conservador, podemos observar núcleos habitacionales incipientes hacia el sur y suroeste, alejados del área central consolidada. Si bien emerge explícitamente una conciencia urbanística, las inversiones se localizaron, básicamente, en los sectores turísticos de la ciudad:

“...dar amplitud a la tan concurrida avenida costanera (...) modernizar y ampliar el alumbrado de las explanadas (...) es urgente la iluminación del camino al Parque Camet..."[12] 
A comienzos de la década de 1950 se produce un completamiento urbano de la zona sur y, en menor medida, hacia el norte, proceso paralelo al reconocimiento oficial de 5 barrios externos al área urbana central.

Esta dinámica se profundiza hacia fines de la década, produciéndose una expansión hacia el suroeste en forma continua, mientras que hacia el norte se produce una urbanización "a saltos", características que se reproducen hasta fines de 1960. Es de destacar que la acción del Estado se reduce a acompañar este proceso sólo con la provisión de alumbrado público. Los servicios básicos de agua y cloacas presentan un fuerte retraso, fundamentalmente en el oeste y suroeste de la ciudad. Será a partir de 1977 que se dinamiza el abastecimiento de la red cloacal, llegando en 1988 a cubrir aproximadamente casi el $90 \%$ de la planta urbana, no así el agua corriente.[13] Concretamente, el alumbrado público y el pavimento son los servicios que acompañan relativamente la planta urbana construida, no sólo por la facilidad de su provisión sino que son los que permiten al municipio la percepción de Tasas.

Por otra parte, como puede observarse en el Cuadro $N^{0} 1$, sí hay desde el Estado una lógica de fragmentación y reunificación espacial que verdaderamente acompaña la dinámica de expansión de la planta urbana construida. Un claro ejemplo de lo que venimos exponiendo, lo constituye el caso del Barrio Autódromo, localizado fuera del ejido urbano, el cual sin haber sido reconocido todavía como barrio por ser un loteo irregular, el Estado crea por Ordenanza su Asociación vecinal desde 1993 (ver Mapas $N^{0} 1$ a 5 ).

\section{CUADRO No 1}

Normativa municipal sobre Asociaciones Vecinales de Fomento Partido General Pueyrredón, 1942-1998.

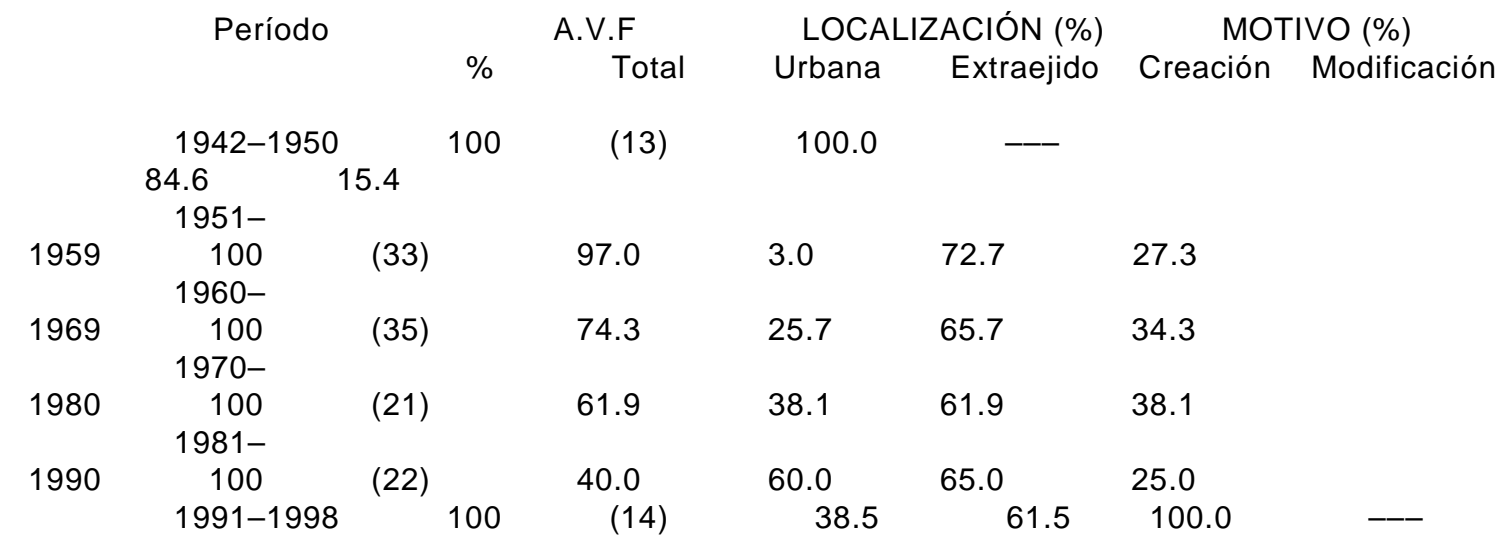

Fuente: Digesto Municipal.

Mapa 1

Localización de las asociaciones vecinales de fomento. Mar del Plata 1940-1950. Elaborado por GISAU en base a datos del Digesto Municipal. 


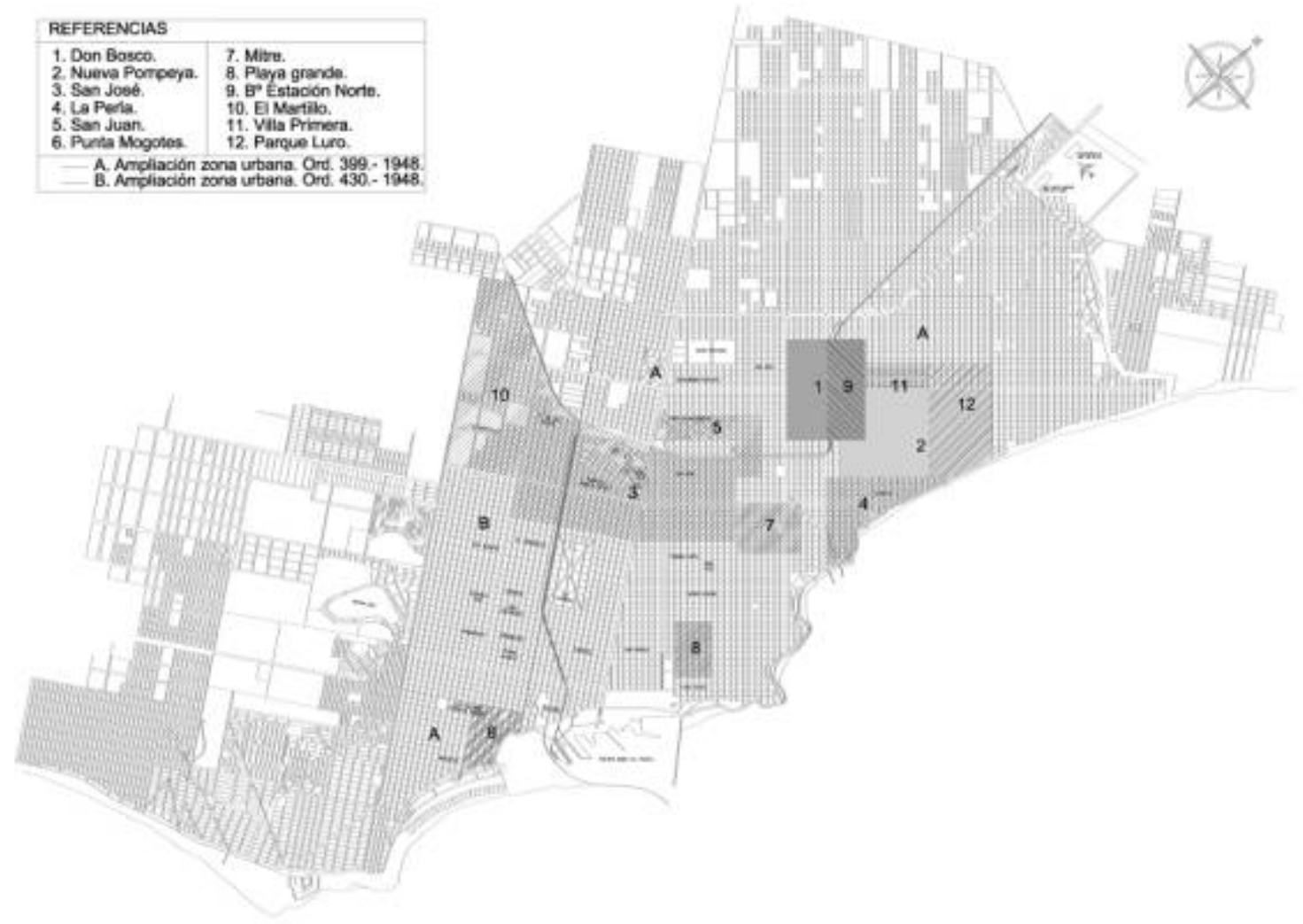

Mapa 2

Localización de las asociaciones vecinales de fomento. Mar del Plata 1951-1960. Elaborado por GISAU en base a datos del Digesto Municipal.

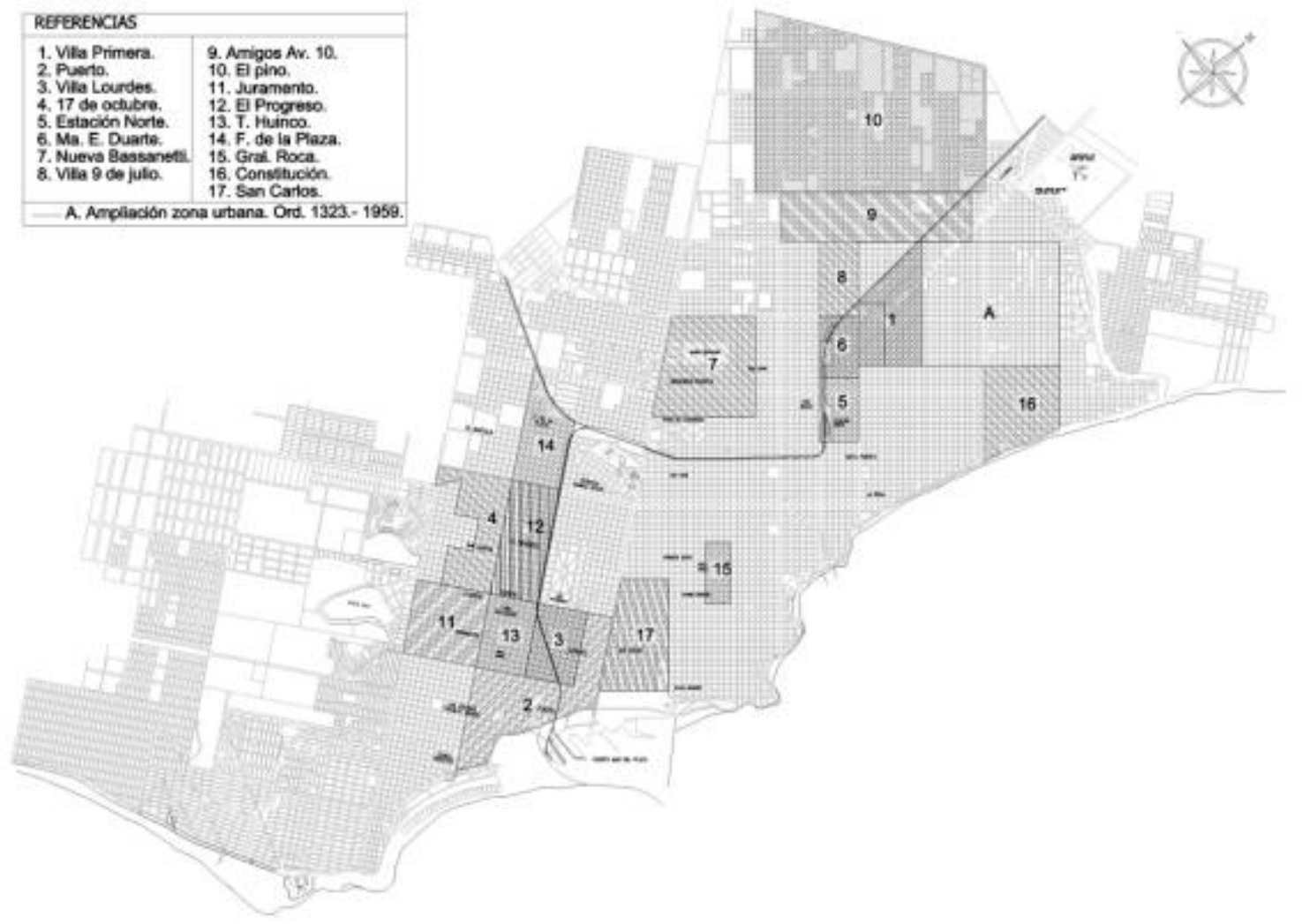




\section{Mapa 3}

Localización de las asociaciones vecinales de fomento. Mar del Plata 1961-1970.

Elaborado por GISAU en base a datos del Digesto Municipal.

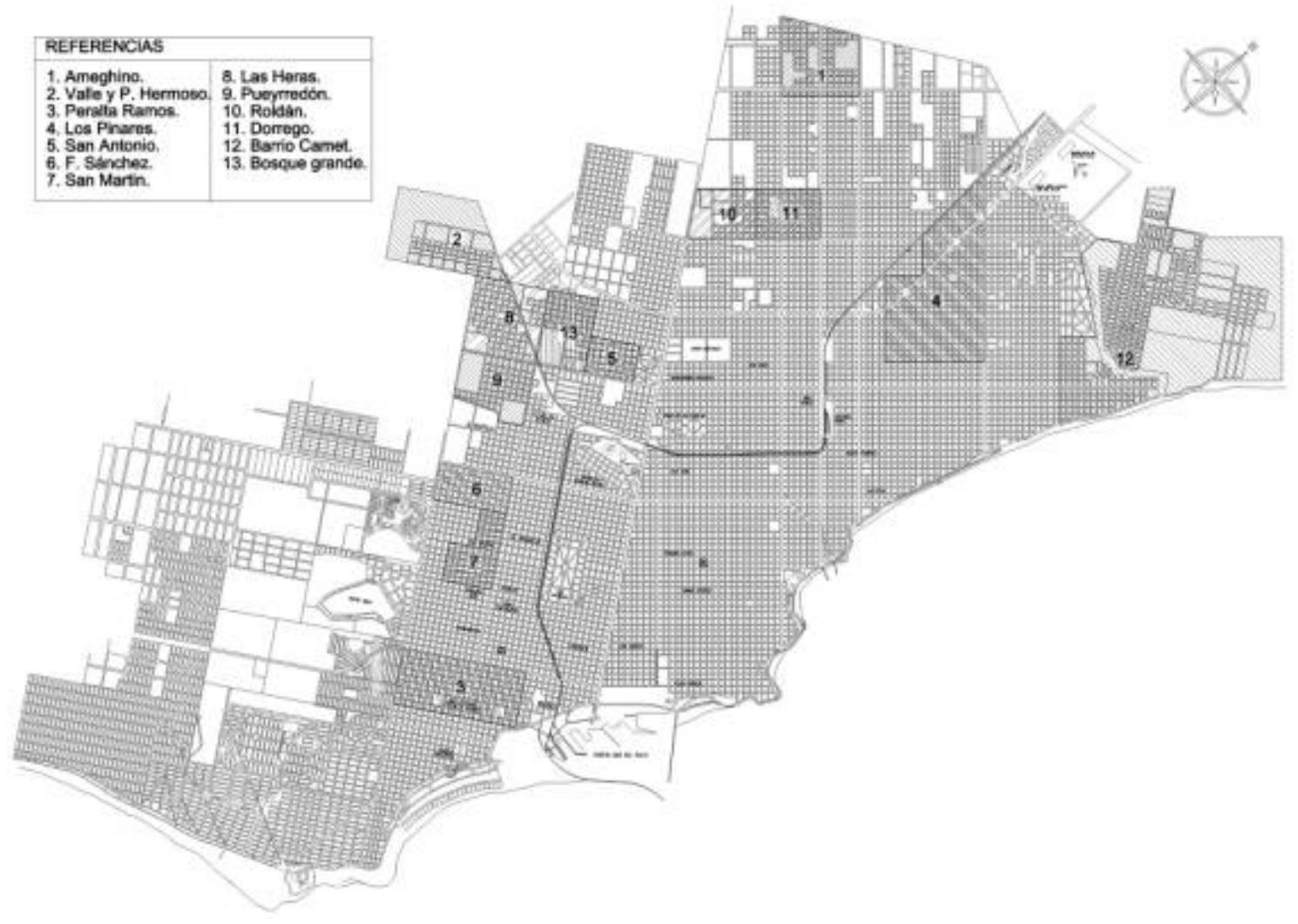

Mapa 4

Localización de las asociaciones vecinales de fomento. Mar del Plata 1971-1996. Elaborado por GISAU en base a datos del Digesto Municipal. 


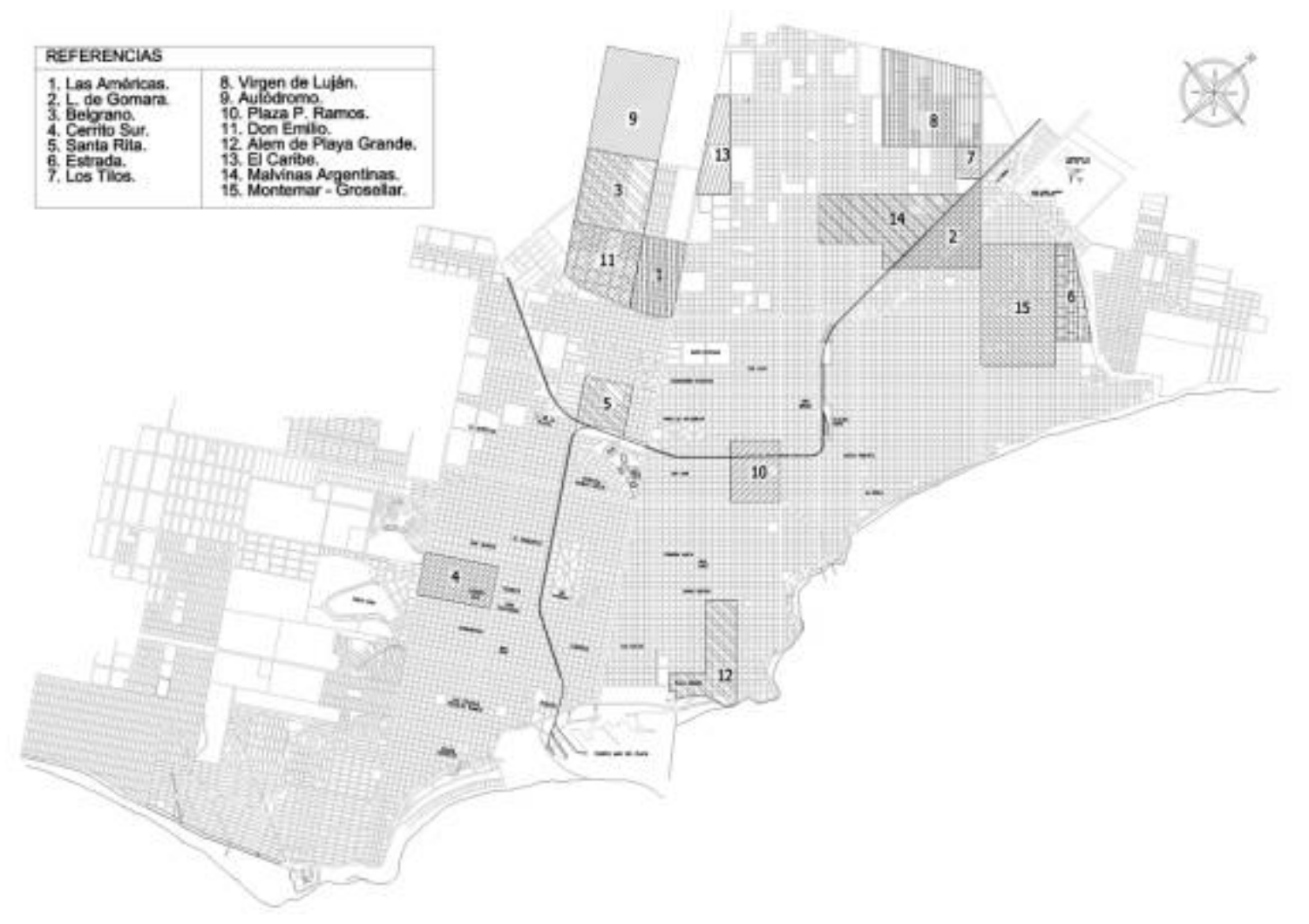

Mapa 5

Localización de las asociaciones vecinales de fomento extraejidales. Gral. Pueyrredón 1960-1995. Elaborado por GISAU en base a datos del Digesto Municipal. 


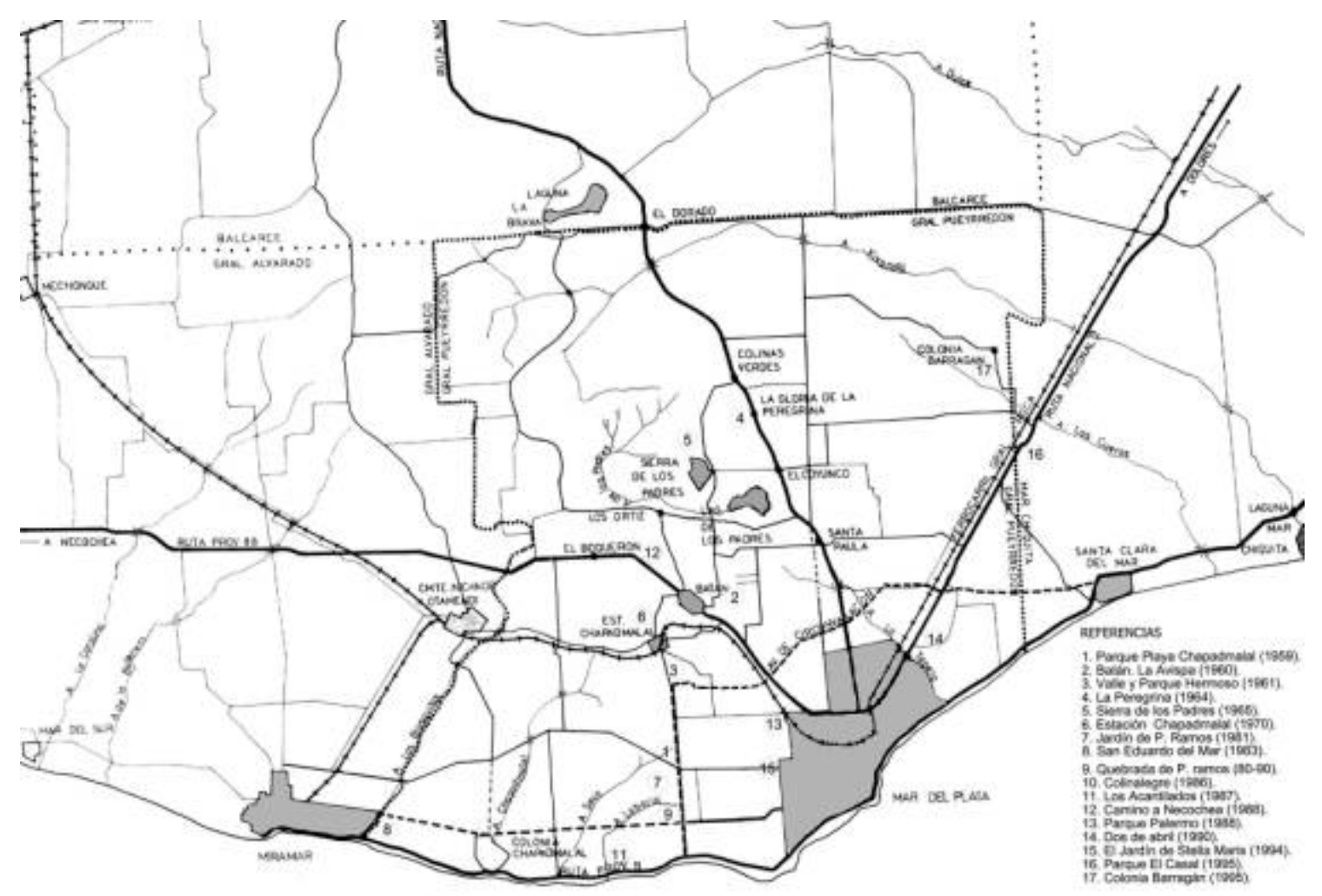

Entre el segundo y el tercer período, es cuando en Mar del Plata se consolida el turismo de masas, proceso que llevará al gobierno municipal a reforzar las inversiones en el área céntrica, dejando de lado los reclamos barriales. Esta toma de decisiones se verá potenciada por la Ley Nacional de Propiedad Horizontal 13512, que permitirá una particularización en el área centro de la ciudad como maximización de la renta diferencial (vivienda "secundaria como mercancía"). Pero, a la vez, en el lapso intercensal 1947-1960 es cuando se registra la mayor inmigración interna y de países limítrofes, surgiendo el boom de los loteos en la periferia como estrategia del capital incorporador, creando un proceso paralelo de horizontalización, de la vivienda como bien de uso.

El 15 de junio de 1957, se realiza en la ciudad el primer Congreso de Entidades de Fomento, reflejando así la importancia del fomentismo en la esfera local, reafirmado por la conducción socialista de la ciudad entre 1958 y 1966.

En 1958 se crea la Secretaría de Obras Públicas y Planeamiento (Ordenanza N 906), teniendo como uno de sus objetivos llevar adelante un Plan Regulador. Para concientizar a la población de la importancia de este plan, el Intendente designa por decreto (No. 1025/58) una Comisión Municipal de Planea-miento, con carácter autónomo, conformada por representantes de diferentes sectores de la ciudad (colegios profesionales, estudiantes, empresarios y asociaciones vecinales de fomento). Entre los fundamentos de creación se prioriza la necesidad de que:

"... el pueblo tome parte activa en el quehacer del planeamiento como saludable ejercitación democrática, a fin de que se arraigue en la conciencia de la colectividad la idea de que no debe ni puede esperarse todo de la acción que le compete a la administración pública." $[14]$

La intendencia de Martí Garro representa para el movimiento vecinal, una de las etapas mas oscuras de su historia. Allí se cierra la Secretaria de Sociedades de Fomento que funcionaba en la sede del Palacio Comunal, desde 1957 y los canales de diálogo institucional y de participación adquieren un bajo perfil de acción colectiva. 
En 1974, durante el segundo período justicialista y en el marco de una comuna socialista a cargo de Fabrizio, se realiza un nuevo Congreso vecinalista y como hecho descollante se crea la COENFO, una organización que nuclea las asociaciones de fomento de la Provincia de Buenos Aires. Este hecho significó una apertura del movimiento a nivel provincial y nacional y una fortificación de sus redes sociales locales.

Aquí se produce un nuevo punto de inflexión en las formas de acción: se modifican las formas de peticionar, los vecinos reclaman la satisfacción de sus necesidades, básicas y no básicas, a través de las asociaciones de fomento que canalizarán las demandas que antes eran satisfechas por el Estado, pasando de la gestión a la cogestión; en los actores: se produce una mayor inserción de técnicos en el movimiento vecinal. Los contenidos que giran en torno a los problemas concretos del ámbito barrial (seguridad, infraestructura de servicios básicos y medios de consumo colectivo) nuclearon, en esta etapa, al movimiento fomentista.

Durante el P.R.N. (1976-83) el gobierno municipal, alternativamente a cargo de Mario Russak, Luis Fabrizio y Zabaleta, focalizó la inversión pública en infraestructura destinada a la captación de recursos a través del turismo de masas: la construcción de la Peatonal San Martín y su fuente, el Complejo Punta Mogotes, la reestructuración de la Av. Constitución y la construcción del Estadio mundialista son ejemplos evidentes. Sin embargo no propició la solución de problemas concretos tales como el abastecimiento de agua potable para un amplio sector de la ciudad. Este sesgo en la orientación social que tomó la comuna local durante el interregno de la dictadura, estímulo la emergencia de nuevas estrategias de participación en el movimiento vecinalista marplatense.

GRÁFICO No 1

Gastos por finalidad (\%). MGP, 1985-1995.

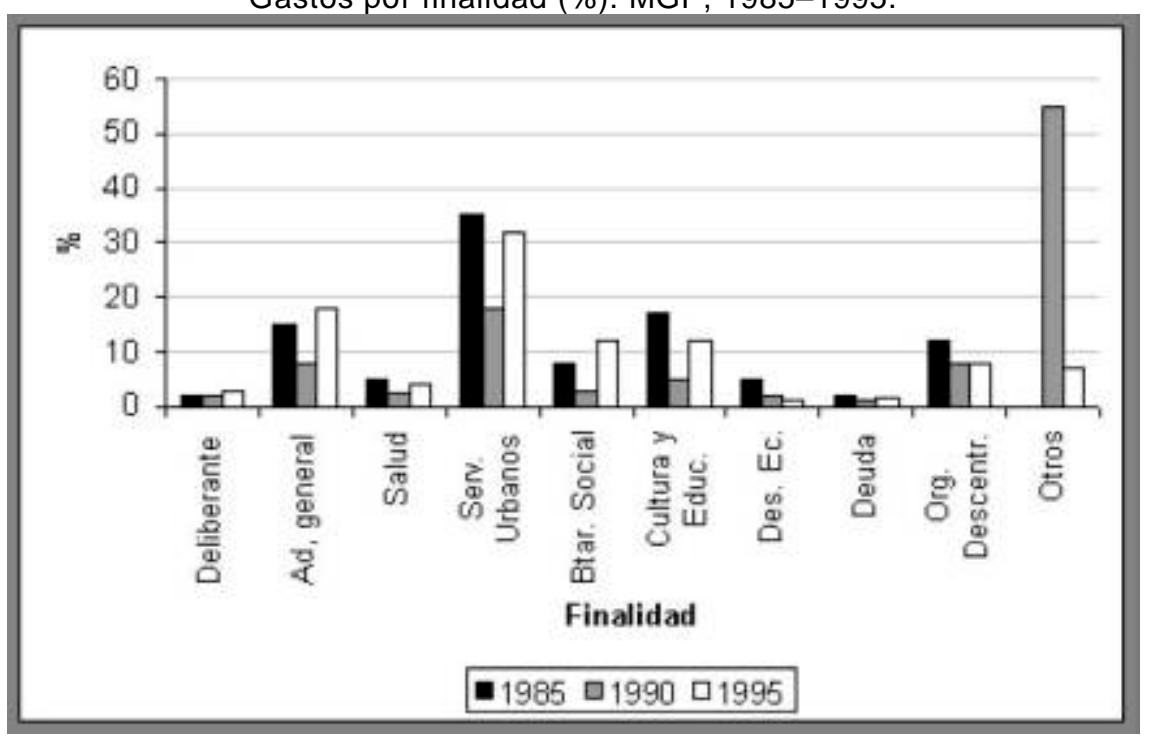

Fuente: Nuñez (1998).

La tercera etapa de «control y explosión participativa», que comienza con el advenimiento de la democracia, alcanza su máxima expresión con el "vecinazo" de 1988, bajo la intendencia del radical Ángel Roig, cuando vecinos de los 17 barrios del Acueducto Sur, como acto simbólico frente a la falta de equidad en la distribución de agua potable, se movilizaron para lavar la ropa en la fuente ubicada en la peatonal San Martín en plena temporada veraniega. A raíz de esta acción colectiva se aprueba la construcción del Acueducto.

Reafirmando lo que venimos exponiendo, se observa en el Gráfico № 1 la composición porcentual de los gastos municipales por finalidad, sobresaliendo en el periodo considerado, los servicios especiales urbanos. Asimismo, confrontando la información con el Cuadro $N^{0} 2$, se evidencia el incremento en gastos corrientes, es decir, personal y servicios. Es de destacar que entre 1985 y 1995 la municipalidad incrementó en 1000 personas sus recursos humanos, lo que debe interpretarse más 
como parte de la organización del aparato administrativo y del desarrollo de redes política locales, que como política de subsidio a los sectores desempleados, ya que el sector público sólo absorbe el $16 \%$ de la población económicamente activa (Nuñez, 1998).

\section{CUADRO № 2}

Orientación del gasto (\%). MGP, 1980-1985.

\section{GASTOS}

\section{CORRIENTES}

De operación

- Personal

- Servicios

Transferencias

-Deuda

GASTOS DE CAPITAL

Inversión

- Obras y equipamiento 32

Inversión financiera 20,5

- Transferencia de capital 0,7

- Amortización deuda

- Otros

\section{2,8}

1980

1985

Fuente: Nuñez (1998).

17,0

46,9

$44,5 \quad 76,2$

$22,2 \quad 43,6$

$22,3 \quad 32,6$

$2,4 \quad 3,2$

$2,4 \quad 3,2$

$53,1 \quad 20,6$

$32,6 \quad 7,0$

7,0

13,6

1,3

1,3

11,0

\section{CONSIDERACIONES FINALES}

Históricamente, la trama local de los actores vinculados a la producción y gestión de la ciudad presentó una imbricación muy estrecha entre los actores estatales, económicos y políticos, dirigidos a consolidar un proyecto de ciudad como objeto privado, abriendo una brecha entre recursos y satisfacción de necesidades de reproducción de la población. Esto se manifestó a partir de las decisiones de orientar las inversiones, como vimos, a los sectores urbanos destinados a la reproducción del capital y, fundamentalmente, tendientes a la valorización del espacio. Los actores políticos estatales no logran tener una presencia importante en los problemas de la ciudad y la competencia que le ha sido atribuida a Mar del Plata y el papel económico diferenciado que presenta, hace que la gestión local se dirija menos a la calidad de vida de la población que a la creación y mantenimiento de las condiciones generales de producción.

Si la ciudad es una forma particular de sociabilidad que se caracteriza por una relación particular entre sociedad y territorio, se debería incluir efectivamente, dice Coraggio, a las mayorías populares en el proceso político local. En 1990 el movimiento vecinalista logra una importante reivindicación a partir de la derogación por el Concejo Deliberante, del artículo 27 del decreto 15, que prohibía el nucleamiento de asociaciones fomentistas en una federación. Esta conquista, representa el triunfo de la acción colectiva y la transición de un vecinalismo "tradicional" a un vecinalismo "emergente".[15]

En 1991 se crea la Federación de Asociaciones Vecinalistas Marplatenses cuya dirigencia estaba a cargo, entre otros, de los actores que propulsaban los valores del "vecinalismo emergente". A partir de 1993 en que se produce un cambio en la comisión directiva de los miembros de la Federación, comienza a hacerse manifiesta la diferencia entre las utopías. La contradicción de valores, contenidos y formas de acción entre los actores que lideran el movimiento vecinalista marplatense hace eclosión en una asamblea realizada en la segunda mitad de 1994, donde las luchas de poder llegan a provocar la fractura del movimiento. Aquellos que lideraron la obra del Acueducto Sur se retiran y en febrero de 1995 crean el "Movimiento Vecinalista Marplatense de Cara al País".

Hacia 1999, el municipio impulsa un nuevo proyecto de descentralización y nueva fragmentación del espacio en Municentros, que plantea una nueva relación Estado/vecinos. Frente a esta superposición de jurisdicciones entre el Consejo Vecinal y el accionar de las asociaciones, cabe preguntarnos si esta propuesta que amenaza la supervivencia de las sociedades de fomento, posibilitar el surgimiento de una nueva utopía de unidad fomentista, que replantee la relación con el poder simbólico del Estado. 
El desarrollo de las acciones llevadas adelante por estos agentes nos permitiría, en trabajos posteriores, profundizar y establecer vinculaciones en la relación Estado/vecinos. En el análisis de dicha relación sería posible visualizar en qué medida la diferente estructura y volumen de capital de los actores sociales intervinientes contribuye a la construcción de identidades socio-espaciales.

\section{BIBLIOGRAFÍA}

ANSART, P.

1993. Marx y la teoría del imaginario social. En Colombo, E. (comp.): El imaginario social, Montevideo, Piedra Libre $N^{\circ} 3$, Nordan, Altamira, (3 reimpresión).

BÉRTOLO, A.

1993. El imaginario subversivo, en Colombo, E., op. cit.

BOURDIEU, P.

1997. Razones prácticas. Sobre la teoría de la acción, Barcelona, Anagrama.

1993. Cosas dichas, Barcelona, Gedisa.

DOS SANTOS, T.

1986. "Crisis y movimientos sociales en Brasil. En Calderón, M.: Los movimientos sociales ante la crisis, Buenos Aires, CLACSO.

GARCÍA DELGADO, D.

1989. "El movimiento vecinal y la democracia: participación y control en el Gran Buenos Aires" En Jelín, E.: Los nuevos movimientos sociales, Buenos Aires, CEAL.

GOLPE, L., NUÑEZ, A. Y BELLOC, C.

1995. Hacia una aproximación del Vecinalismo Marplatense en el marco de los Movimientos Sociales Urbanos, inédito.

GRANER, E.

1991. "¿Otro discurso sin sujeto? Apuntes sobre el poder, la cultura y las identidades sociales". En El cielo por asalto, año 1, $\mathrm{N}^{\circ}$. 1, Buenos Aires, Ed. Imago Mundi.

LAUROU, R.

1993. "El Estado inconsciente". En Colombo, E. op. cit.

NUÑEZ, A.

1998. Gestión urbana en una ciudad turística argentina. En Revista Interamericana de

Planificación, vol. XXX, N.117-118.

NUÑEZ, A. Y CACOPARDO, F.

1999. "Trazado, urbanismo y ocupación territorial en una ciudad intermedia argentina. Mar del Plata", 1874-1950, Topos, vol. 1, N. 1, Universidade Federal de Minas Gerais.

OFFE, C.

1988. Partidos políticos y nuevos movimientos sociales, Madrid, Sistema.

PASTORIZA, E.

1989. "La formación de una ciudad moderna: grupos sociales y ámbitos culturales", en AA.VV.: Mar del Plata, una historia urbana, Mar del Plata, FBB.

1993. Los trabajadores de Mar del Plata en vísperas del peronismo, Bs. As., CEAL.

VIÑAS, MA.

2000. Garantizar la participación para fortalecer la democracia, Mar del Plata, Municipalidad de Gral. Pueyrredón, Bloque del FREPASO.

[1] Esto significó, en líneas generales, poner en práctica un conjunto de medidas tendientes a mejorar el estado de salud de la población, la limpieza y alumbrado de los espacios públicos y el fomento de las actividades deportivas. Esta preocupación se enmarca en un pensamiento que tuvo su correlato a nivel internacional en los estudios que abordaron los problemas del desarrollo urbano.

[2] Ordenanza del 24 de febrero de 1892. 
[3] Ordenanza del 28 de febrero de 1899.

[4] Manifiesto del 9 de febrero de 1920 publicado por la comisión provisoria, en Comisión Pro- Mar del Plata: "Memoria. Presentada a la asamblea de vecinos y veraneantes celebrada el día 27 de febrero de 1921", Buenos Aires, 1921.

[5] La Comisión estaba formada por 71 miembros (un Presidente, dos Vice Presidentes, dos Secretarios, un Tesorero y 65 vocales). Entre sus miembros naturales incluidos en el estatuto se encuentran el Intendente de General Pueyrredón, y los Presidentes del Jockey Club de Capital Federal, del Club Mar del Plata, del Mar del Plata Golf Club, del Ocean Club, del Yachtmen Club y del Tiro a la Paloma. Esta comisión podía sesionar tanto en Mar del Plata como en Capital Federal. Ver "Estatuto de Fundación de la Comisión Mar del Plata, 14 de febrero de 1920", en Comisión Pro-mar del Plata: "Memoria. Presentada a la asamblea de vecinos y veraneantes celebrada el día 27 de febrero de 1920", Buenos Aires, 1921.

[6] Estas prácticas darán como resultado la constitución de numerosas entidades de socorros mutuos, colectividades, clubes deportivos y culturales, bibliotecas barriales. Ver: entre otros, A.A.V.V. (1999): Mar del Plata, de la prehistoria a la actualidad. Caras y contracaras de una ciudad imaginada, Grupo HISA, Facultad de Humanidades UNMDP. También, Pastoriza, E. (1993).

[7] En Belloc, C.; Golpe, L., y Nuñez, A. (1995).

[8] La Ordenanza 314 establece los objetivos y condiciones para la formación de Asociaciones Vecinales de Fomento. Dentro de los primeros se destacan las responsabilidades de velar por el mejoramiento edilicio y el cumplimiento de las ordenanzas municipales, dentro de la jurisdicción asignada, denunciando las deficiencias que se constaten. Asimismo deben cooperar en la organización de los servicios de asistencia social y en la difusión de la cultura popular. Entre las condiciones para su formación se establece que deben contar con un mínimo de 100 socios, su radio de acción no será menor de treinta manzanas, designar por votación una Comisión Directiva y elaborar un estatuto que deberá ser aprobado por el municipio.

[9] Entrevista realizada a Washington Píriz, 1995. En ibidem.

[10] Boletín Municipal, 1924. Ver el trabajo de Nuñez, A, y Cacopardo, F. (1999).

[11] Ibidem.

[12] Boletín Municipal, 1937.

[13] En el año 1991, por Decreto del Intendente Mario Russak, se declara la utilidad pública y el pago obligatorio de los servicios de agua corriente y cloacas dentro del ejido urbano, fundamentalmente por el cólera.

[14] Ver Viñas, M. (2000).

[15] García Delgado, D.\& Silva, J. R. (1989). 